\title{
Temperature effect on photolysis decomposing of perfluorooctanoic acid
}

\author{
Tiliang Zhang, Gang Pan*, Qin Zhou \\ Research Center for Eco-Environmental Sciences, Chinese Academy of Sciences, Beijing 100085, China. E-mail: tiliangzhang@126.com
}

\section{A R T I C L E I N F O}

\section{Article history:}

Received 1 April 2015

Revised 7 May 2015

Accepted 11 May 2015

Available online 2 July 2015

Keywords:

Perfluorooctanoic acid

PFOA

Photolysis

Temperature effect

\begin{abstract}
A B S T R A C T
Perfluorooctanoic acid (PFOA) is recalcitrant to degrade and mineralize. Here, the effect of temperature on the photolytic decomposition of PFOA was investigated. The decomposition of PFOA was enhanced from $34 \%$ to $99 \%$ in $60 \mathrm{~min}$ of exposure when the temperature was increased from 25 to $85^{\circ} \mathrm{C}$ under UV light $(201-600 \mathrm{~nm})$. The limited degree of decomposition at $25^{\circ} \mathrm{C}$ was due to low quantum yield, which was increased by a factor of 12 at $85^{\circ} \mathrm{C}$. Under the imposed conditions, the defluorination ratio increased from $8 \%$ at $25^{\circ} \mathrm{C}$ to $50 \%$ at $85^{\circ} \mathrm{C}$ in $60 \mathrm{~min}$. Production of perfluorinated carboxylic acids (PFCAs, C7-C5), PFCAs (C4-C3) and TFA (trifluoroacetic acid, C2) accelerated and attained a maximum within 30 to $90 \mathrm{~min}$ at $85^{\circ} \mathrm{C}$. However, these reactions did not occur at $25^{\circ} \mathrm{C}$ despite extended irradiation to 180 min. PFOA was decomposed in a step-wise process by surrendering one $\mathrm{CF}_{2}$ unit. In each cyclical process, increased temperature enhanced the quantum yields of irradiation and reactions between water molecules and intermediates radicals. The energy consumption for removing each $\mu \mathrm{mol}$ of PFOA was reduced from $82.5 \mathrm{~kJ}$ at $25^{\circ} \mathrm{C}$ to $10.9 \mathrm{~kJ}$ at $85^{\circ} \mathrm{C}$ using photolysis. Photolysis coupled with heat achieved high rates of PFOA degradation and defluorination.
\end{abstract}

() 2015 The Research Center for Eco-Environmental Sciences, Chinese Academy of Sciences. Published by Elsevier B.V.

\section{Introduction}

Perfluorooctanoic acid (PFOA, $\mathrm{CF}_{3}\left(\mathrm{CF}_{2}\right)_{6} \mathrm{COOH}$ ) is a member of the class of substances called perfluorinated chemicals (PFCs). PFOA has been produced and used in commercial products and industrial processes for over 60 years (Renner, 2004; Lindstrom et al., 2011). Interest and concern about PFOA are growing as more are learned about this anthropogenic chemical. PFOA is resistant to environmental degradation and has the potential for bioaccumulation (Post et al., 2012). PFOA enhances the health risks, including endocrine disrupting properties (White et al., 2011), immunotoxicity (DeWitt et al., 2012) and developmental effects (Fletcher et al., 2013). PFOA is different from other persistent organic pollutants in its hydrotrope property and can therefore aggregate in the liver and blood serum rather than in fatty tissues (Gebbink et al., 2009). Although the manufacture and use of PFOA are phasing out in some countries, PFOA has been frequently detected in drinking water (Post et al., 2009; Quinones and Snyder, 2009), biotas (Gebbink et al., 2009) and in people (Harada et al., 2007). However, PFOA is difficult to degrade using most conventional technologies (Vecitis et al., 2009). Thus, it is important and urgent to find an effective mineralization method.

Recently, a number of chemical technologies for PFOA decomposition have been reported. These methods cover various chemical process, including thermally-induced reduction (Krusic et al., 2005), microwave assisted oxidative decomposition (Lee et al., 2009, 2010), sonochemical pyrolysis

\footnotetext{
* Corresponding author. E-mail: gpan6@yahoo.co.uk (Gang Pan).
} 
(Vecitis et al., 2008; Cheng et al., 2010; Moriwaki et al., 2005), electrochemical degradation (Zhuo et al., 2011; Niu et al., 2012; Lin et al., 2012b) and photochemical decomposition (Wang et al., 2008, 2010; Wang and Zhang, 2011; Song et al., 2012). Among these reported methods, sonochemical, electrochemical and photochemical degradations are the most promising treatment alternatives to degrade PFOA efficiently. In the case of photochemical decomposition, there have been a number of attempts to promote the degradation of PFOA. Direct photolysis, as a clean technique, is limited by the low degradation efficiency and inadequate mineralization (Hori et al., 2004a). The indirect photoreactions have been developed to improve the efficiency of photo degradation. Some oxidants, such as ozone (Lin et al., 2012a), persulfate (Hori et al., 2005) and ferric ion (Hori et al., 2007), have been found to enhance the degradation and mineralization of PFOA. However, these methods require chemical compounds that are potential secondary pollutants. Photocatalysts have also been investigated for PFOA degradation. Titanium dioxide materials offer the advantage of generating hydroxyl radicals (HO) in aqueous solution to help degrade most organic pollutant (Hoffmann et al., 1995), but HO is not sufficiently effective to degrade PFOA $\left(k_{\mathrm{OH}}+\mathrm{PFOA} \leq 10^{5}(\mathrm{~mol} / \mathrm{L})^{-1} \cdot \mathrm{sec}^{-1}\right)$. The electronegative fluoride atoms in PFOA reduce the electron density of the terminal -COO- group and are thus inimical to electron transfer between $\mathrm{HO}$ and the -COO- group (Vecitis et al., 2009). Indium oxide $\left(\mathrm{In}_{2} \mathrm{O}_{3}\right)$ exhibits remarkable photocatalytic activity for PFOA decomposition. The tightly bidentate compound or the bridging configuration of PFOA molecule to the $\mathrm{In}_{2} \mathrm{O}_{3}$ surface enhances the direct decomposition of PFOA by photogenerated holes in $\mathrm{In}_{2} \mathrm{O}_{3}$ under UV irradiation (Li et al., 2012a). Nanostructured $\operatorname{In}_{2} \mathrm{O}_{3}$ with greater oxygen vacancy defects shows higher photocatalytic activity (Li et al., 2012b, 2013). However, the mineralization is inadequate, because degradation products may deplete the oxygen vacancy defects of the photocatalysts. As a result, it is essential to explore a more efficient and clean method for the removal and mineralization of PFOA.

Water molecules involved in reacting with intermediates in the decomposition processes of PFOA. The reaction temperature exhibits significant influence on the decomposing efficiency (Lee et al., 2010; Xiao et al., 2011). The low solution temperature $\left(20^{\circ} \mathrm{C}\right)$ in persulfate oxidation systems requires $648 \mathrm{hr}$ to degrade $81 \%$ of PFOA (Lee et al., 2012), whereas hot water $\left(80^{\circ} \mathrm{C}\right)$ persulfate oxidative systems can completely degrade PFOA in $6 \mathrm{hr}$ (Hori et al., 2008). This acceleration is attributed to the abundant sulfate radicals which were formed quickly at high temperature to degrade PFOA. In the electrochemical degradation of PFOA by a boron-doped diamond film electrode, the apparent reaction rate constant increased from 0.108 to $0.444 \mathrm{hr}^{-1}$ as reaction temperature increased from 20 to $100^{\circ} \mathrm{C}$ (Xiao et al., 2011). In the photolysis processes for decomposing PFOA, intermediate reactions involved with the water molecules have been reported (Hori et al., 2004a; Chen et al., 2007). However, there have been few reports concerning the temperature effects on the PFOA photolysis degradation.

Photolysis is a clean PFOA treatment approach. However, it is constrained by poor efficiency and limited mineralization. There are two practical approaches to enhance the photolysis efficiency of PFOA, which include application of deep ultraviolet light and the promotion of quantum yields. PFOA has a strong absorption peak centered at $190 \mathrm{~nm}$ and a general broad light absorption from 220 to $600 \mathrm{~nm}$. The combination of $185 \mathrm{~nm}$ and $254 \mathrm{~nm}$ could achieve higher degradation efficiency than $185 \mathrm{~nm}$ (Chen et al., 2007; Giri et al., 2011). Therefore, compound light may achieve high PFOA degradation efficiency. The quantum yield describes the ratio of the absorbed photons that transform the pollutant. This is dependent on the probability of the excited-state achieved by absorbed photon and their ability promotes the reaction to products (Schwarzenbach et al., 2003). The promotion of the quantum yield of the irradiated light will enhance the PFOA degradation. Nevertheless, there have been few reports to investigate the temperature effect on the quantum yield and the photolysis reaction for degrading PFOA up to now.

The main objective of this study is to explore the temperature effect on the photolytic degradation of PFOA. The quantum yield of compound light at various temperatures was calculated and discussed. The production of intermediates and fluoride ions was investigated. The potential for temperature elevation to enhance the degradation or the mineralization of PFOA by photolysis was explored.

\section{Materials and methods}

\subsection{Standards and chemicals}

Perfluorooctanoic acid (PFOA, sodium salt, 97\%, CAS NO.: 335-67-1) was purchased from Aldrich Chemical Co. (New Jersey, USA). Methanol (HPLC grade) was purchased from Fisher Scientific (Pittsburgh, USA). Ammonium acetate (LC-MS Ultra, CAS NO.: 631-61-8) was purchased from Sigma-Aldrich Co. LLC. (Shanghai, China). All other chemicals used in this work were of analytical grade. An aqueous solution of PFOA was prepared using high purity water $(18.2 \mathrm{M} \Omega \cdot \mathrm{cm})$ obtained from the Milli-Q Ultrapure Water Purification Systems (Millipore, Boston, USA).

\subsection{Photolysis experiments}

The photolysis experiments were conducted in a tubular quartz reactor with an inner diameter of $55 \mathrm{~mm}$ and a length of $250 \mathrm{~mm}$ (Appendix A Fig. S1). A high-pressure mercuryvapor lamp (500 W, Beijing Lighting Research Institute, China) was used to provide UV illumination. The emission spectrum of the mercury-vapor lamp is shown in Appendix A Fig. S1. The lamp with a quartz envelope was placed in the center of the reactor. The reaction temperature was controlled by a thermal water jacket around the reactor (Appendix A Fig. S1).

The initial concentration of PFOA was set at $30 \mathrm{mg} / \mathrm{L}$. The reactor was filled with a volume of $500 \mathrm{~mL}$ PFOA aqueous solution. The temperature of photoreaction solution was controlled from 25 to $85^{\circ} \mathrm{C}$ by circulating water in a bainmarie with a peristaltic pump. Two microliter aliquots of the photoreaction solution were periodically collected for analysis of PFOA and intermediates at intervals of $0,30,60,90,120$ and $180 \mathrm{~min}$ during the reaction. In addition, an additional $2 \mathrm{~mL}$ aliquot of the photoreaction solution was collected for determination of fluoride ions. 


\subsection{Analysis}

An ultra-performance liquid chromatography-tandem mass spectrometry (UPLC-MS/MS) was used to determine the concentrations of PFOA and identify the photolysis intermediates. The UPLC system (Waters Corp., Massachusetts, USA) was equipped with a C18 column $(2.1 \mathrm{~mm} \times 50 \mathrm{~mm}$ i.d., particle size $1.7 \mathrm{~mm}$, Waters Corp., USA). The MS system was a Quattro Premier XE tandem quadrupole mass spectrometer (Waters Corp., Massachusetts, USA) with an electrospray ionization source. The analytical method has been described previously (Zhou et al., 2013; Zhuo et al., 2012). The mobile phase was a binary mixture of solvent A ( $2 \mathrm{mmol} / \mathrm{L}$ ammonium acetate in 5\% methanol) and solvent B (2 mmol/L ammonium acetate in $100 \%$ methanol) at a flow rate of $0.3 \mathrm{~mL} / \mathrm{min}$. The solvent gradient began with $25 \% \mathrm{~A}$ and $75 \% \mathrm{~B}$, and was linearly ramped to $85 \% \mathrm{~A}$ and $15 \% \mathrm{~B}$ in $5 \mathrm{~min}$, then ramped to $25 \% \mathrm{~A}$ and $75 \% \mathrm{~B}$ in the following $2 \mathrm{~min}$. The column was then allowed to equilibrate for $3 \mathrm{~min}$ and the total running time was $10 \mathrm{~min}$. The injection volume of the samples was $10 \mu \mathrm{L}$. The tandem MS analysis was conducted in the multiple reaction monitoring modes, and the cone voltage and collision energy were $30 \mathrm{~V}$ and $11 \mathrm{~V}$, respectively. Standard solutions contained PFOA and some C2-C7 shorter-chain PFCAs. Calibration standards were prepared in the range of 10-900 $\mu \mathrm{g} / \mathrm{L}$ POFA.

The concentration of fluoride ions $\left(\mathrm{F}^{-}\right)$in aqueous solution were determined using an ion-chromatography system (Dionex-ICS2000, Sunnyvale, USA) consisting of manual sample injector (sample injection volume: $25 \mu \mathrm{L}$ ), degasser, pump, separation column $(250 \mathrm{~mm}$ length $\times 4 \mathrm{~mm}$ i.d., Dionex Ionpac AS11-HC, Sunnyvale, USA), column oven $\left(30^{\circ} \mathrm{C}\right)$ and conductivity detector with a suppressor device. The mobile phase consisted of a solution of $\mathrm{KOH}(30 \mathrm{mmol} / \mathrm{L})$ which was pumped into the system at a rate of $1.0 \mathrm{~mL} / \mathrm{min}$. The limit of detection was $0.01 \mathrm{mg} / \mathrm{L}$. Defluorination ratio was calculated as follow (Eq. (1)).

Def $=\frac{C_{\mathrm{F}^{-}}}{15 \times C_{\mathrm{PFOA}}} \times 100 \%$

where, Def is the defluorination ratio, $C_{F-}(\mathrm{mmol} / \mathrm{L})$ is the concentration of fluoride ion, $C_{\mathrm{PFOA}}(\mathrm{mmol} / \mathrm{L})$ is the initial concentration of PFOA and the constant 15 corresponds to the number of fluorine atoms in PFOA molecule.

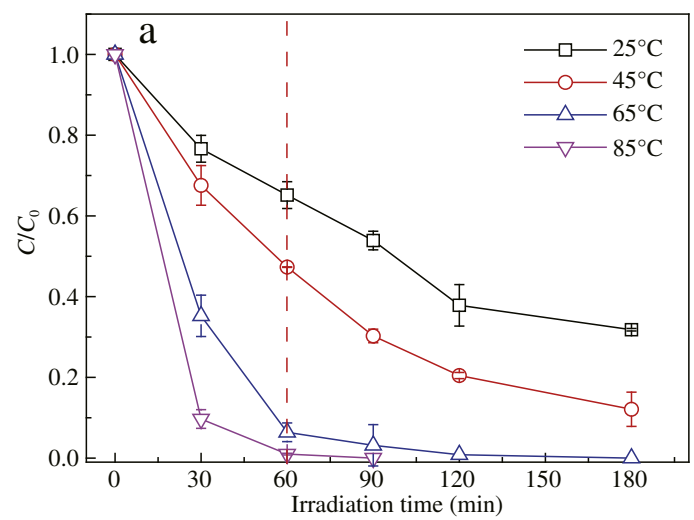

\section{Results}

\subsection{Degradation kinetics of PFOA}

The concentration of PFOA decreased with irradiation time, which was remarkably enhanced as temperature of the reaction system was increased (Fig. 1). The decrease in the concentration of PFOA in solution went from $39 \%$ at $25^{\circ} \mathrm{C}$ to $99 \%$ at $85^{\circ} \mathrm{C}$ within $60 \mathrm{~min}$ (Fig. 1a). The decrease of PFOA followed first-order kinetics at the various temperatures (Fig. 1b, Appendix A Table S1). The reaction rate constants increased from $6.40 \times 10^{-3} \mathrm{~min}^{-1}$ at $25^{\circ} \mathrm{C}$ to $7.71 \times 10^{-2} \mathrm{~min}^{-1}$ at $85^{\circ} \mathrm{C}$.

\subsection{Defluorination}

Fluoride ions were generated during the photolysis reaction, which increased as the temperature increased (Fig. 2). Defluorination ratio at $25^{\circ} \mathrm{C}$ was $8 \%$, which increased to $50 \%$ at $85^{\circ} \mathrm{C}$ within $60 \mathrm{~min}$. The defluorination ratio increased continuously to $77 \%$ at $85^{\circ} \mathrm{C}$ from $60 \mathrm{~min}$ to $180 \mathrm{~min}$.

\subsection{Degradation intermediates}

The samples collected at different temperatures were analyzed by UPLC-MS/MS chromatograms to identify intermediate products. According to the mass-charge ratio of the fragment ions, the intermediate products were identified as short chain PFCAs bearing C7-C2 perfluoroalkyl groups, including PFHpA $\left(\mathrm{C}_{6} \mathrm{~F}_{13} \mathrm{COO}^{-}\right)$, PFHxA $\left(\mathrm{C}_{5} \mathrm{~F}_{11} \mathrm{COO}^{-}\right)$, PFPeA $\left(\mathrm{C}_{4} \mathrm{~F}_{9} \mathrm{COO}^{-}\right)$, PFBA $\left(\mathrm{C}_{3} \mathrm{~F}_{7} \mathrm{COO}^{-}\right)$, PFPrA $\left(\mathrm{C}_{2} \mathrm{~F}_{5} \mathrm{COO}^{-}\right)$and TFA $\left(\mathrm{CF}_{3} \mathrm{COO}^{-}\right)$(Fig. 3 and Appendix A Fig. S3).

With the degradation of PFOA at $25^{\circ} \mathrm{C}$ (Fig. 1a), PFCA (C7C3) formation followed the order of chain length from PFHpA (C7) to TFA (C2). PFHpA (C7) was detected immediately. PFHxA (C6), PFPeA (C5), PFBA (C4) and PFPrA (C3) were detected at 30, 30,60 and $180 \mathrm{~min}$. TFA (C2) was not detected after $180 \mathrm{~min}$ of irradiation (Fig. 3a).

The production of PFCAs accelerated as the temperature was increased (Fig. 3 and Appendix A Table S3). At $25^{\circ} \mathrm{C}$, PFCAs (C7-C2) were produced slowly and did not attain the maximum generation even after extended irradiation times to $180 \mathrm{~min}$. At

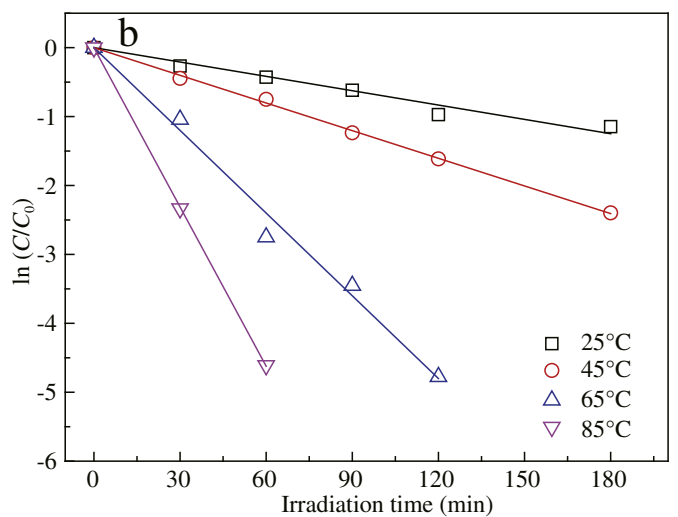

Fig. 1 - Photolytic decomposition of perfluorooctanoic acid (PFOA) (a) and first-order plots of PFOA degradation (b) at different temperatures. 


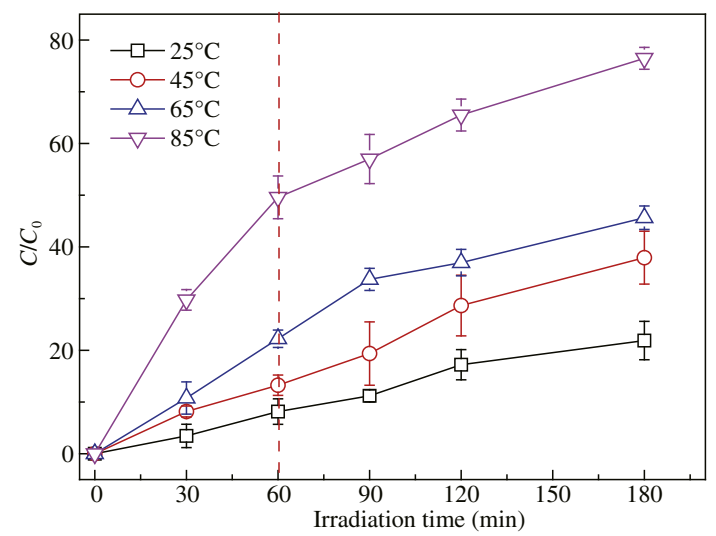

Fig. 2 - Defluorination ratios of PFOA at different temperatures. PFOA: perfluorooctanoic acid.

$85^{\circ} \mathrm{C}$, PFCAs (C7-C5), PFCAs (C4-C3) and TFA (C2) formed quickly and were at maximum concentration within 30,60 and $90 \mathrm{~min}$, respectively.

At high reaction temperatures, PFCA (C7-C2) formation also followed the order of chain length from PFHpA (C7) to TFA (C2) (Fig. 3b-d). PFHpA (C7), PFHxA (C6) and PFPeA (C5) formed first and achieved maximum concentration within $30 \mathrm{~min}$. Following this, PFBA (C4) and PFPrA (C3) formed and achieved maximum concentration within 60 and $90 \mathrm{~min}$, respectively. TFA (C2) generation did not achieve maximum concentration within $180 \mathrm{~min}$ (Fig. 3C).

\section{Discussion}

\subsection{Effect of temperature on PFOA photolysis}

It is well known that the efficiency of direct photolysis is limited by quantum efficiency and the intensity of the irradiating light, in which the intensity is increased at the cost of energy consumption (Hori et al., 2004a; Cao et al., 2010). The quantum yield is the number of degraded PFOA molecules divided by the number of photons absorbed by the system. The quantum yields at different temperatures were calculated according to Appendix Eq. (S1). The quantum yields increased with temperature and obeyed Eq. (2) (Fig. 4).

$\Phi=402.6 \times \exp \left(\frac{-4424.6}{T+273}\right)$

After the PFOA molecule absorbed a photon, it became unstable and underwent two competing processes in the experimental photoreaction system. These processes included degradation or internal conversion to heat, which were initiated to return the molecule to a stable state (Zepp and Cline, 1977). High reaction temperatures inhibited the internal conversion to heat and favored the degradation process of PFOA. The promotion of quantum yield illustrates an increase in the proportion of PFOA molecules existing at an excited state that are involved in the degradation process. The quantum yield $\left(1.72 \times 10^{-3}\right)$ at $85^{\circ} \mathrm{C}$ was twelve times higher than that $\left(1.55 \times 10^{-4}\right)$ at $25^{\circ} \mathrm{C}$ (Fig. 4 and Appendix A Table S1).
Temperature elevation promoted the quantum yields and thus enhanced the photolysis of PFOA.

\subsection{Effect of temperature on the degradation of PFCA interme- diates and mineralization}

The defluorination ratio increased by $50 \%$ when $99 \%$ PFOA was degraded in $60 \mathrm{~min}$ at $85^{\circ} \mathrm{C}$ (Figs. 2 and 1a), whereas the defluorination ratio continually increased to $77 \%$ (Fig. 2) from 60 to $180 \mathrm{~min}$ (Fig. 3d). The additional fluoride ions generated during the reaction from 60 to 180 min resulted from the degradation of PFCAs intermediates. Hydrogen ions were also simultaneously generated (Fig. 5). The long chain PFCAs were degraded to fluoride ions, hydrogen ions and short chain PFCAs containing fewer $\mathrm{CF}_{2}$ units (Figs. 2, 3 and 5).

The degradation of PFHpA (C7), PFHxA (C6) achieved their maximum concentration within $60 \mathrm{~min}$ at $45^{\circ} \mathrm{C}$ (Fig. $3 \mathrm{~b}$ ), but this process was observed within $30 \mathrm{~min}$ at $65^{\circ} \mathrm{C}$ (Fig. 3c). Obviously, the degradation of PFHpA (C7) was accelerated by increasing the temperature from 45 to $65^{\circ} \mathrm{C}$. Similarly, with the degradation of PFPeA (C5), PFBA (C4) occurred and achieved maximum concentration at $65^{\circ} \mathrm{C}$, but not at $45^{\circ} \mathrm{C}$ (Fig. $3 \mathrm{~b}$ and c). This illustrated that the degradation of PFPeA (C5) was also enhanced as temperature was increased. These phenomena were also investigated in the other PFCAs intermediates (Fig. 3b, c, d and Appendix A Table S3). Higher reaction temperatures promoted the degradation of PFCAs into hydrogen ions, fluoride ions and short chain PFCAs.

Defluorination ratio was directly related to the degree of PFOA mineralization. The increase in the defluorination ratio suggested that PFOA was directly degraded to fluoride ions and carbon dioxide (Lee et al., 2012). Temperature elevation promoted the production of hydrogen ions and fluoride ions (Figs. 2 and 5). The mineralization of PFOA by photolysis was promoted by increased reaction temperature.

\subsection{Mechanism of PFOA degradation}

As illustrated above, when the PFOA was degraded, the defluorination ratio increased continually so that PFCA intermediates were formed and decomposed, $\mathrm{pH}$ values decreased and these processes were enhanced with increasing temperature (Figs. 1, 2, 3 and 5). The PFOA was decomposed into short chain PFCAs, fluoride ions and hydrogen ions at $85^{\circ} \mathrm{C}$ with pattern similar to that at $25^{\circ} \mathrm{C}$, i.e. direct photolysis. Based on the results and direct photolysis, the mechanism of the temperature effects on photolysis to degrade PFOA is proposed.

The reaction temperatures $\left(\leq 85^{\circ} \mathrm{C}\right)$ are far below the thermolysis temperature $\left(350^{\circ} \mathrm{C}\right)$ and were not sufficient to degrade PFOA without irradiation (Krusic and Roe, 2004; Krusic et al., 2005). The $\mathrm{C}-\mathrm{C}$ bond between $\mathrm{C}_{7} \mathrm{~F}_{15}$ and $\mathrm{COOH}$ is the weakest bond in the PFOA chemical structure because the fluorine atom has the strongest inductive electron withdrawal ability (Blondel et al., 1989). The light irradiation initially cleaves this weakest bond, which initiates the PFOA degradation. As a result, $\mathrm{C}_{7} \mathrm{~F}_{15}$ radicals and carbon dioxide are generated in this step (Eq. (3)). The increasing reaction temperature promotes the quantum yield of the irradiating 

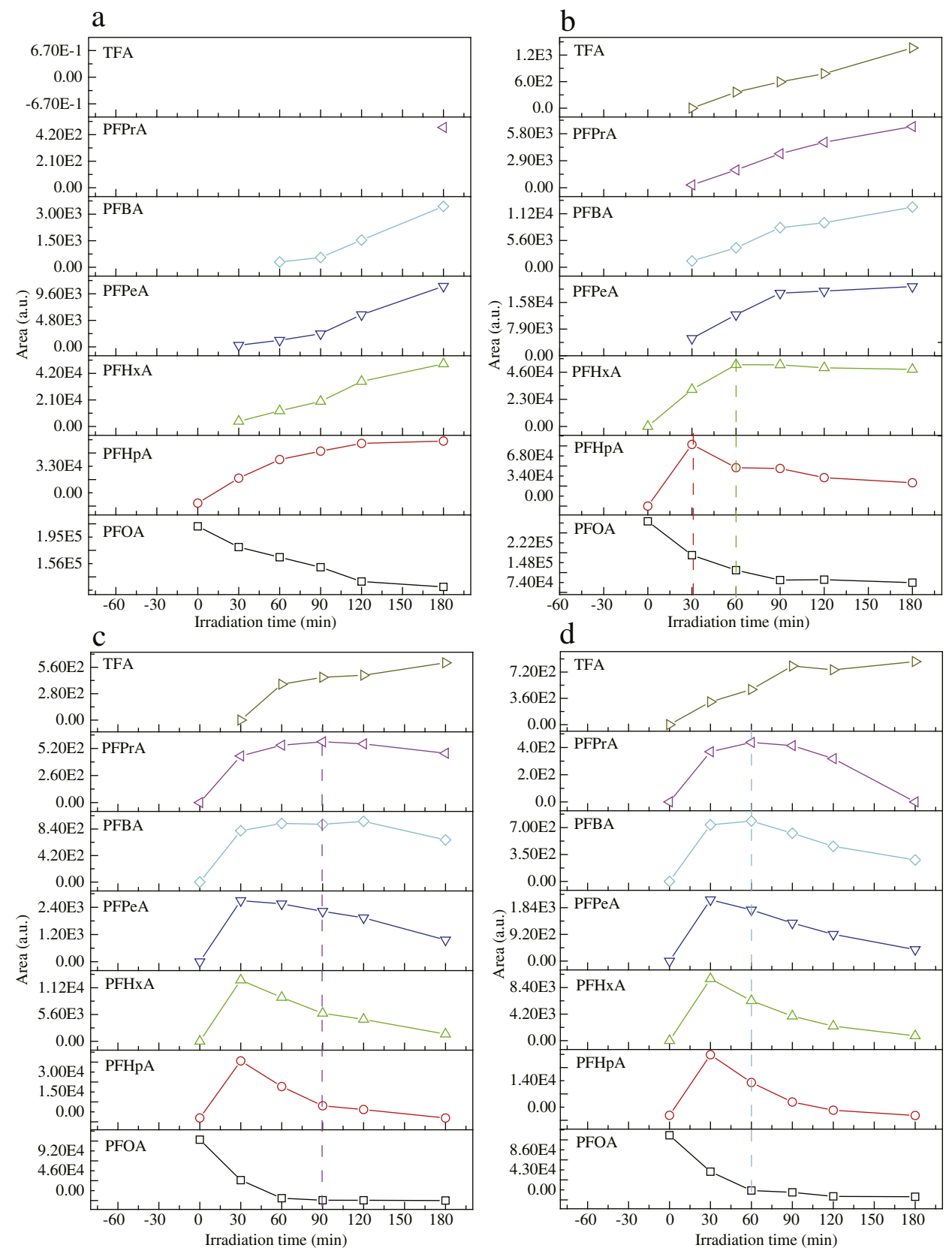

Fig. 3 - Time course of shorter-chain intermediates at $25^{\circ} \mathrm{C}(\mathrm{a}), 45^{\circ} \mathrm{C}(\mathrm{b}), 65^{\circ} \mathrm{C}$ (c) and $85^{\circ} \mathrm{C}$ (d).

light and the population of PFOA molecules at excited state involved in degradation process is increased (Fig. 1, Eq. (2)).

$\mathrm{C}_{7} \mathrm{~F}_{15} \mathrm{COO}^{-} \stackrel{\text { hv\&heat }}{\longrightarrow} \mathrm{C}_{7} \mathrm{~F}_{15} \cdot+\mathrm{CO}_{2}+\mathrm{e}^{-}$

The end carbon atom of $\mathrm{C}_{7} \mathrm{~F}_{15}$. radical possesses high electric charge intensity (Hori et al., 2004a; Chen et al., 2007), which prefers to react with electrophilic oxidants (Hori et al., 2003a, 2003b, 2004b; Dillert et al., 2007). For direct photolysis, the electrophilic oxidants are oxygen in the reaction solution or water molecules of the reaction solution (Niu et al., 2013; Gatto et al., 2015; Mitchell et al., 2013). The $\mathrm{C}_{6} \mathrm{~F}_{13} \mathrm{C}^{16} \mathrm{O}^{18} \mathrm{O}$ and $\mathrm{C}_{6} \mathrm{~F}_{13} \mathrm{C}^{18} \mathrm{O}^{18} \mathrm{O}$ are the main intermediates resulting from direct irradiation of PFOA in $\mathrm{H}_{2}^{18} \mathrm{O}$ solutions under high oxygen pressure (Hori et al., 2004a). This proves that the water molecule in solution is the main oxidative source. Consequently, primary perfluoroalcohols $\mathrm{C}_{7} \mathrm{~F}_{15} \mathrm{OH}$ are produced. $\mathrm{C}_{7} \mathrm{~F}_{15} \mathrm{OH}$ is thermodynamically unstable and generates acyl fluorides $\left(\mathrm{C}_{6} \mathrm{~F}_{13} \mathrm{COF}\right)$ by releasing $\mathrm{HF}$ (Eq. (4)).

$\mathrm{C}_{7} \mathrm{~F}_{15} \mathrm{OH} \stackrel{\text { heat }}{\longrightarrow} \mathrm{C}_{6} \mathrm{~F}_{13} \mathrm{COF}+\mathrm{H}^{+}+\mathrm{F}^{-}$

Hydrogen ions are continuously generated (Fig. 4) and there was no other hydrogen source in the solution except the water molecule. In fact, $\mathrm{C}_{6} \mathrm{~F}_{13} \mathrm{COF}$ is immediately hydrolyzed in water (Eq. (5)). By this process, $\mathrm{PFHpA}\left(\mathrm{C}_{6} \mathrm{~F}_{13} \mathrm{COO}^{-}\right)$, fluoride ions and hydrogen ions are formed.

$\mathrm{C}_{6} \mathrm{~F}_{13} \mathrm{COF}+\mathrm{H}_{2} \mathrm{O} \stackrel{\text { heat }}{\longrightarrow} \mathrm{C}_{6} \mathrm{~F}_{13} \mathrm{COO}^{-}+2 \mathrm{H}^{+}+\mathrm{F}^{-}$ 


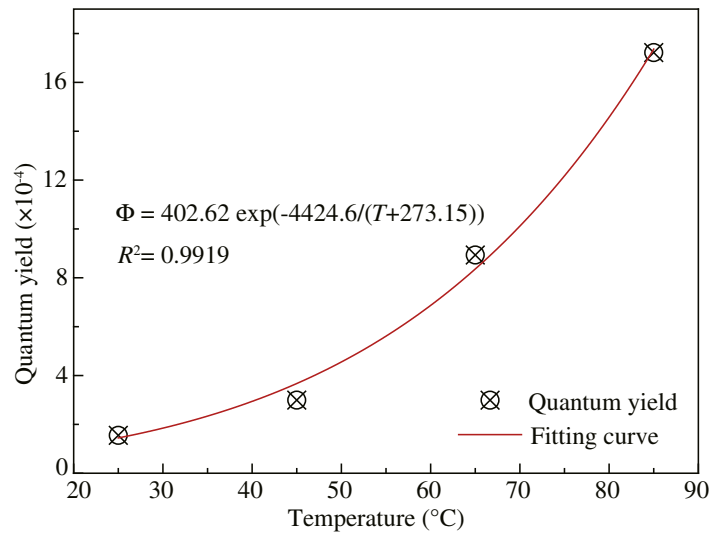

Fig. 4 - Quantum yield and fitting curve on the temperature.

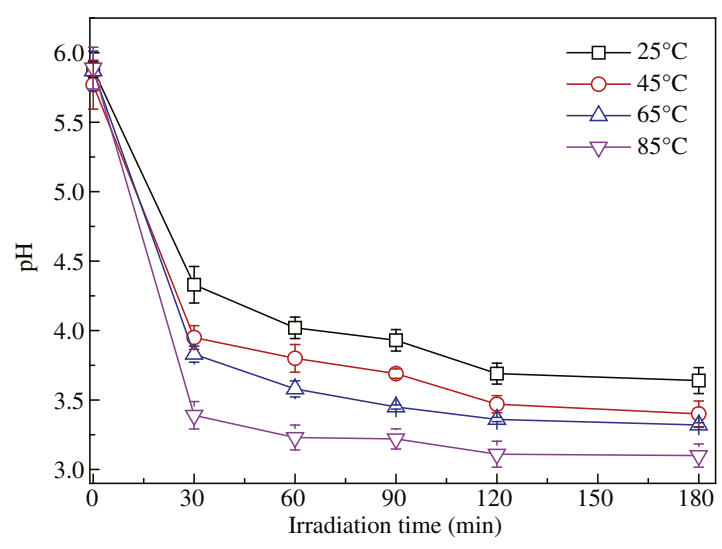

Fig. 5 - Time course of $\mathrm{pH}$ values in the photolysis processes at different temperatures.

The generation of PFCA intermediates in sequence from PFHpA (C7) to TFA (C2) (Fig. 3) suggests that PFOA is degraded by losing $\mathrm{CF}_{2}$ units in a step-by-step process. In the same way, the resulting PFCAs are decomposed into fluoride ions, carbon dioxide and the short chain PFCAs with less one $\mathrm{CF}_{2}$ unit. In each cyclical process of losing one $\mathrm{CF}_{2}$ unit, the increasing temperature promotes the quantum yield (Eqs. (2) and (3)) and the hydrolysis reaction (Eqs. (4) and (5)). Finally, PFOA is decomposed into fluoride ions and carbon dioxide.

\subsection{Environmental implications}

Until recently, there has been little interest in the photolytic degradation of POFA, because of its low efficiency and inadequate mineralization capability. As presented in this study, the photolysis efficiency and mineralization of PFOA were enhanced by increasing the temperature of reaction solution (Figs. 1 and 2). By increasing the reaction temperature to $85^{\circ} \mathrm{C}$, the total energy consumption is reduced. Furthermore, the photolysis technique requires no additional chemical regents.

The energy consumption was calculated based on the reaction conditions, initial concentrations and degradation kinetics (Vecitis et al., 2009). At the initial concentration $30 \mathrm{mg} / \mathrm{L}(72.5 \mu \mathrm{mol} / \mathrm{L})$, the energy consumed to remove $15 \mathrm{mg} / \mathrm{L}$ PFOA was $2997 \mathrm{~kJ}$ at $25^{\circ} \mathrm{C}$ (Table 1), due mainly to light energy consumption, because the half-life was $99.9 \mathrm{~min}$. Although the energy consumption for elevating the solution temperature increased, the half-life was shortened and the required light energy was decreased, so that the total energy consumption was thus reduced. The energy consumption to remove $1 \mu \mathrm{mol}$ PFOA was reduced from $82.5 \mathrm{~kJ}$ at $25^{\circ} \mathrm{C}$ to $10.9 \mathrm{~kJ}$ at $85^{\circ} \mathrm{C}$ (Table 1).

In addition to the lower energy consumption, photolysis, coupled with temperature, is a clean and green technique, which mitigates the adverse effects of secondary pollution, which are inevitable for numerous photochemical methods, especially those that demand photocatalysts or chemical reagents. This study supplies a clean and efficient approach to decompose PFOA.

\section{Conclusions}

The degradation of PFOA by photolysis coupled with temperature was investigated in this study. The photolysis of PFOA is accelerated due to the enhancement of quantum yield as the temperature is increased. PFOA is decomposed into fluoride ions, hydrogen ions and short chain PFCAs in sequence from PFHpA (C7) to TFA (C2). The mechanism for PFOA degradation begins with the loss of a $\mathrm{CF}_{2}$ unit in a step-by-step process. In each cyclical degradation process from long chain PFCAs to short chain PFCAs with one less $\mathrm{CF}_{2}$ unit, the quantum yields of irradiation light and the hydrolysis reaction are enhanced when the reaction temperature is increased. The promotional effect of temperature in each cyclically process of losing one

Table 1 - Energy consumption for perfluorooctanoic acid (PFOA) degradation at different temperatures.

\begin{tabular}{cccccc}
$\mathrm{T}\left({ }^{\circ} \mathrm{C}\right)$ & Half-life $\left(\tau_{1 / 2}, \mathrm{~min}\right)$ & Light energy $(\mathrm{kJ})^{\mathrm{a}}$ & $\mathrm{Q}(\mathrm{kJ})^{\mathrm{b}}$ & Total energy $(\mathrm{kJ})^{\text {Energy }(\mathrm{kJ} / \mu \mathrm{mol})^{\mathrm{c}}}$ \\
\hline 25 & 99.9 & 2997 & 0 & 2997 & 82.5 \\
45 & 51.8 & 1554 & 42 & 1596 & 43.9 \\
65 & 17.3 & 519 & 84 & 603 & 16.6 \\
85 & 9.0 & 270 & 126 & 396 & 10.9 \\
\hline
\end{tabular}

${ }^{a}$ Light energy was calculated by the power of mercury lamp (500 W) and the time of half-life.

$\mathrm{b} Q$ was the energy consuming for elevating the temperature of photoreaction solution $(500 \mathrm{~mL})$ calculated by the formula

$\mathrm{Q}=4.2 \mathrm{~kJ} / \mathrm{kg} \times 0.5 \mathrm{~kg} \times(\mathrm{T}-25)$.

${ }^{c}$ Energy consumption for per $\mu \mathrm{mol}$ was calculated on the required energy to reduce PFOA to half of its initial concentration $(30 \mathrm{mg} / \mathrm{L})$. 
$\mathrm{CF}_{2}$ unit also strengthens the mineralization of the photolysis. The energy consumption for removing $1 \mu \mathrm{mol}$ PFOA is reduced from $82.5 \mathrm{~kJ}$ at $25^{\circ} \mathrm{C}$ to $10.9 \mathrm{~kJ}$ at $85^{\circ} \mathrm{C}$. This study provides an exploration on the application of thermal effects in the photolytic degradation of PFOA.

\section{Acknowledgments}

This work was supported by the National Basic Research Program (973) of China (No. 2010CB933600), the Strategic Priority Research Program of the Chinese Academy of Sciences (No. XDA09030203), the National Natural Science Foundation of China (Nos. 21277161, 41103076), the special fund from the State Key Laboratory of Environmental Aquatic Chemistry (No. 10Y10ESPCR), and the Youth Innovation Promotion Association, Chinese Academy of Sciences (29QNCX2012005).

\section{Appendix A. Supplementary data}

Supplementary data associated with this article can be found in online version at http://dx.doi.org/10.1016/j.jes.2015.05.008.

\section{REFERENCES}

Blondel, C., Cacciani, P., Delsart, C., Trainham, R., 1989. High-resolution determination of the electron affinity of fluorine and bromine using crossed ion and laser beams. Phys. Rev. A 40, 3698-3701.

Cao, M.H., Wang, B.B., Yu, H.S., Wang, L.L., Yuan, S.H., Chen, J., 2010. Photochemical decomposition of perfluorooctanoic acid in aqueous periodate with VUV and UV light irradiation. J. Hazard. Mater. 179, 1143-1146.

Chen, J., Zhang, P.Y., Liu, J., 2007. Photodegradation of perfluorooctanoic acid by $185 \mathrm{~nm}$ vacuum ultraviolet light. J. Environ. Sci. (China) 19, 387-390.

Cheng, J., Vecitis, C.D., Park, H., Mader, B.T., Hoffmann, M.R., 2010. Sonochemical degradation of perfluorooctane sulfonate (PFOS) and perfluorooctanoate (PFOA) in groundwater: kinetic effects of matrix inorganics. Environ. Sci. Technol. 44, 445-450.

DeWitt, J.C., Peden-Adams, M.M., Keller, J.M., Germolec, D.R., 2012. Immunotoxicity of perfluorinated compounds: recent developments. Toxicol. Pathol. 40, 300-311.

Dillert, R., Bahnemann, D., Hidaka, H., 2007. Light-induced degradation of perfluorocarboxylic acids in the presence of titanium dioxide. Chemosphere 67, 785-792.

Fletcher, T., Galloway, T.S., Melzer, D., Holcroft, P., Cipelli, R., Pilling, L.C., et al., 2013. Associations between PFOA, PFOS and changes in the expression of genes involved in cholesterol metabolism in humans. Environ. Int. 57-58C, 2-10.

Gatto, S., Sansotera, M., Persico, F., Gola, M., Pirola, C., Panzeri, W., et al., 2015. Surface fluorination on $\mathrm{TiO}_{2}$ catalyst induced by photodegradation of perfluorooctanoic acid. Catal. Today 241, 8-14 (Part A)

Gebbink, W.A., Hebert, C.E., Letcher, R.J., 2009. Perfluorinated carboxylates and sulfonates and precursor compounds in Herring Gull Eggs from colonies spanning the Laurentian Great Lakes of North America. Environ. Sci. Technol. 43, 7443-7449.

Giri, R.R., Ozaki, H., Morigaki, T., Taniguchi, S., Takanami, R., 2011. UV photolysis of perfluorooctanoic acid (PFOA) in dilute aqueous solution. Water Sci. Technol. 63, 276-282.
Harada, K., Koizumi, A., Saito, N., Inoue, K., Yoshinaga, T., Date, C., et al., 2007. Historical and geographical aspects of the increasing perfluorooctanoate and perfluorooctane sulfonate contamination in human serum in Japan. Chemosphere 66, 293-301.

Hoffmann, M.R., Martin, S.T., Choi, W., Bahnemann, D.W., 1995. Environmental applications of semiconductor photocatalysis. Chem. Rev. 95, 69-96.

Hori, H., Takano, Y., Koike, K., Kutsuna, S., Einaga, H., Ibusuki, T., 2003a. Photochemical decomposition of pentafluoropropionic acid to fluoride ions with a water-soluble heteropolyacid photocatalyst. Appl. Catal. B Environ. 46, 333-340.

Hori, H., Takano, Y., Koike, K., Takeuchi, K., Einaga, H., $2003 \mathrm{~b}$. Decomposition of environmentally persistent trifluoroacetic acid to fluoride ions by a homogeneous photocatalyst in water. Environ. Sci. Technol. 37, 418-422.

Hori, H., Hayakawa, E., Einaga, H., Kutsuna, S., Koike, K., Ibusuki, T., et al., 2004a. Decomposition of environmentally persistent perfluorooctanoic acid in water by photochemical approaches. Environ. Sci. Technol. 38, 6118-6124.

Hori, H., Hayakawa, E., Yamashita, N., Taniyasu, S., Nakata, F., Kobayashi, Y., 2004b. High-performance liquid chromatography with conductimetric detection of perfluorocarboxylic acids and perfluorosulfonates. Chemosphere 57, 273-282.

Hori, H., Yamamoto, A., Hayakawa, E., Taniyasu, S., Yamashita, N., Kutsuna, S., et al., 2005. Efficient decomposition of environmentally persistent perfluorocarboxylic acids by use of persulfate as a photochemical oxidant. Environ. Sci. Technol. 39, 2383-2388.

Hori, H., Yamamoto, A., Koike, K., Kutsuna, S., Osaka, I., Arakawa, R., 2007. Photochemical decomposition of environmentally persistent short-chain perfluorocarboxylic acids in water mediated by iron(II)/(III) redox reactions. Chemosphere 68, 572-578.

Hori, H., Nagaoka, Y., Murayama, M., Kutsuna, S., 2008. Efficient decomposition of perfluorocarboxylic acids and alternative fluorochemical surfactants in hot water. Environ. Sci. Technol. 42, 7438-7443.

Krusic, P.J., Roe, D.C., 2004. Gas-phase NMR technique for studying the thermolysis of materials: thermal decomposition of ammonium perfluorooctanoate. Anal. Chem. 76, 3800-3803.

Krusic, P.J., Marchione, A.A., Roe, D.C., 2005. Gas-phase NMR studies of the thermolysis of perfluorooctanoic acid. J. Fluor. Chem. 126, 1510-1516.

Lee, Y.C., Lo, S.L., Chiueh, P.T., Chang, D.G., 2009. Efficient decomposition of perfluorocarboxylic acids in aqueous solution using microwave-induced persulfate. Water Res. 43, 2811-2816.

Lee, Y.C., Lo, S.L., Chiueh, P.T., Liou, Y.H., Chen, M.L., 2010. Microwave-hydrothermal decomposition of perfluorooctanoic acid in water by iron-activated persulfate oxidation. Water Res. 44, 886-892.

Lee, Y.C., Lo, S.L., Kuo, J., Lin, Y.L., 2012. Persulfate oxidation of perfluorooctanoic acid under the temperatures of 20-40 degrees C. Chem. Eng. J. 198, 27-32.

Li, X.Y., Zhang, P.Y., Jin, L., Shao, T., Li, Z.M., Cao, J.J., 2012a. Efficient photocatalytic decomposition of perfluorooctanoic acid by indium oxide and its mechanism. Environ. Sci. Technol. 46, 5528-5534.

Li, Z.M., Zhang, P.Y., Shao, T., Li, X.Y., 2012b. $\mathrm{In}_{2} \mathrm{O}_{3}$ nanoporous nanosphere: a highly efficient photocatalyst for decomposition of perfluorooctanoic acid. Appl. Catal. B Environ. 125, 350-357.

Li, Z., Zhang, P., Shao, T., Wang, J., Jin, L., Li, X., 2013. Different nanostructured $\mathrm{In}_{2} \mathrm{O}_{3}$ for photocatalytic decomposition of perfluorooctanoic acid (PFOA). J. Hazard. Mater. 260, 40-46.

Lin, A.Y.-C., Panchangam, S.C., Chang, C.-Y., Hong, P.K.A., Hsueh, H.-F., 2012a. Removal of perfluorooctanoic acid and perfluorooctane sulfonate via ozonation under alkaline condition. J. Hazard. Mater. 243, 272-277. 
Lin, H., Niu, J.F., Ding, S.Y., Zhang, L.L., 2012b. Electrochemical degradation of perfluorooctanoic acid (PFOA) by $\mathrm{Ti} / \mathrm{SnO}_{2}-\mathrm{Sb}$, $\mathrm{Ti} / \mathrm{SnO}_{2}-\mathrm{Sb} / \mathrm{PbO}_{2}$ and $\mathrm{Ti} / \mathrm{SnO}_{2}-\mathrm{Sb} / \mathrm{MnO}_{2}$ anodes. Water Res. 46, 2281-2289.

Lindstrom, A.B., Strynar, M.J., Libelo, E.L., 2011. Polyfluorinated compounds: past, present, and future. Environ. Sci. Technol. 45, 7954-7961.

Mitchell, S.M., Ahmad, M., Teel, A.L., Watts, R.J., 2013. Degradation of perfluorooctanoic acid by reactive species generated through catalyzed $\mathrm{H}_{2} \mathrm{O}_{2}$ propagation reactions. Environ. Sci. Technol. Lett. 1, 117-121.

Moriwaki, H., Takagi, Y., Tanaka, M., Tsuruho, K., Okitsu, K., Maeda, Y., 2005. Sonochemical decomposition of perfluorooctane sulfonate and perfluorooctanoic acid. Environ. Sci. Technol. 39, 3388-3392.

Niu, J.F., Lin, H., Xu, J.L., Wu, H., Li, Y.Y., 2012. Electrochemical mineralization of perfluorocarboxylic acids (PFCAs) by Ce-doped modified porous nanocrystalline $\mathrm{PbO}_{2}$ film electrode. Environ. Sci. Technol. 46, 10191-10198.

Niu, J., Lin, H., Gong, C., Sun, X., 2013. Theoretical and experimental insights into the electrochemical mineralization mechanism of perfluorooctanoic acid. Environ. Sci. Technol. 47, 14341-14349.

Post, G.B., Louis, J.B., Cooper, K.R., Boros-Russo, B.J., Lippincott, R.L., 2009. Occurrence and potential significance of perfluorooctanoic acid (PFOA) detected in New Jersey public drinking water systems. Environ. Sci. Technol. 43, 4547-4554

Post, G.B., Cohn, P.D., Cooper, K.R., 2012. Perfluorooctanoic acid (PFOA), an emerging drinking water contaminant: a critical review of recent literature. Environ. Res. 116, 93-117.

Quinones, O., Snyder, S.A., 2009. Occurrence of perfluoroalkyl carboxylates and sulfonates in drinking water utilities and related waters from the United States. Environ. Sci. Technol. 43, 9089-9095.

Renner, R., 2004. Tracking the dirty byproducts of a world trying to stay clean. Science 306, 1887.

Schwarzenbach, R.P., Gschwend, P.M., Imboden, D.M., 2003. Environmental Organic Chemistry. 2nd ed. John Wiley \& Sons, Hoboken, USA.

Song, C., Chen, P., Wang, C.Y., Zhu, L.Y., 2012. Photodegradation of perfluorooctanoic acid by synthesized $\mathrm{TiO}_{2}$-MWCNT composites under 365 nm UV irradiation. Chemosphere 86, 853-859.
Vecitis, C.D., Park, H., Cheng, J., Mader, B.T., Hoffmann, M.R., 2008. Kinetics and mechanism of the sonolytic conversion of the aqueous perfluorinated surfactants, perfluorooctanoate (PFOA), and perfluorooctane sulfonate (PFOS) into inorganic products. J. Phys. Chem. A 112, 4261-4270.

Vecitis, C.D., Park, H., Cheng, J., Mader, B.T., Hoffmann, M.R., 2009. Treatment technologies for aqueous perfluorooctanesulfonate (PFOS) and perfluorooctanoate (PFOA). Front. Environ. Sci. Eng. 3, 129-151.

Wang, Y., Zhang, P., 2011. Photocatalytic decomposition of perfluorooctanoic acid (PFOA) by $\mathrm{TiO}_{2}$ in the presence of oxalic acid. J. Hazard. Mater. 192, 1869-1875.

Wang, Y., Zhang, P., Pan, G., Chen, H., 2008. Ferric ion mediated photochemical decomposition of perfluorooctanoic acid (PFOA) by $254 \mathrm{~nm}$ UV light. J. Hazard. Mater. 160, 181-186.

Wang, B.B., Cao, M.H., Tan, Z.J., Wang, L.L., Yuan, S.H., Chen, J., 2010. Photochemical decomposition of perfluorodecanoic acid in aqueous solution with VUV light irradiation. J. Hazard. Mater. 181, 187-192.

White, S.S., Fenton, S.E., Hines, E.P., 2011. Endocrine disrupting properties of perfluorooctanoic acid. J. Steroid Biochem. 127, 16-26.

Xiao, H.S., Lv, B.Y., Zhao, G.H., Wang, Y.J., Li, M.F., Li, D.M., 2011. Hydrothermally enhanced electrochemical oxidation of high concentration refractory perfluorooctanoic acid. J. Phys. Chem. A 115, 13836-13841.

Zepp, R.G., Cline, D.M., 1977. Rates of direct photolysis in aquatic environment. Environ. Sci. Technol. 11, 359-366.

Zhou, Q., Pan, G., Zhang, J., 2013. Effective sorption of perfluorooctane sulfonate (PFOS) on hexadecyltrimethylammonium bromide immobilized mesoporous $\mathrm{SiO}_{2}$ hollow sphere. Chemosphere 90, 2461-2466.

Zhuo, Q., Deng, S., Yang, B., Huang, J., Yu, G., 2011. Efficient electrochemical oxidation of perfluorooctanoate using a $\mathrm{Ti} / \mathrm{SnO}_{2}-\mathrm{Sb}-\mathrm{Bi}$ anode. Environ. Sci. Technol. 45, 2973-2979.

Zhuo, Q.F., Deng, S.B., Yang, B., Huang, J., Wang, B., Zhang, T.T., et al., 2012. Degradation of perfluorinated compounds on a boron-doped diamond electrode. Electrochim. Acta 77, 17-22. 